Scripta METALLURGICA et MATERIALIA
Vo1. 29, pp. 69-74, 1993

Printed in the U.S.A.
Pergamon Press Ltd. All rights reserved

\title{
ATOMIC SCALE STUDIES OF THE MECHANISMS OF INTERNAL OXIDATION
}

\author{
Ho Jang, David K. Chan and David N. Seldman \\ Department of Materials Science and Engineering and the Materials Research Center \\ Northwestern University \\ Evanston, IL 60208-3108 USA
}

Karl L. Merkle

Materials Science Division, Building 212

Argonne National Laboratory

Argonne, IL 60439 USA

(Received Apri1 15, 1993)

\section{Introduction}

The phenomenon of internal oxidation of solute atoms, in binary metal alloys, is a venerable one that has been studied off and on since its discovery in 1930 [1]. The diameter and number density of the precipitated metal oxides -- that are the end product of this phenomenon -- depend upon the solute element and its concentration in the alloy, temperature of internal oxidation, external oxygen pressure and time [2,3]. Internal oxidation of alloys has been used to produce dispersion hardened materials in an effort to improve their mechanical properties, and to reduce spallation of alloys; for example, $\mathrm{Ag}(\mathrm{Cd})$ alloys are used to switch medium to high currents [4]. Experimental and theoretical research has demonstrated that to obtain internal oxidation of a solute atom in a solid solution, as opposed to external oxidation of the solvent or solute atoms, several conditions must be met [2,3,5-11]. First, the chemical affinity of oxygen for the solute species must be much greater than for the solvent species. Second, oxygen must diffuse faster in the matrix than does the solute species. The latter can be expressed in terms of the relative permeabilities $\left(D_{i} C_{i}\right)$ of oxygen and solute atoms in the metal matrix; internal oxidation of a binary alloy results in a ternary system -- solvent, solute and oxygen atoms. Thus internal oxidation may occur if $D_{0} C_{O} \gg D_{S} C_{S}-$ where $D_{i}$ represents diffusivity, $C_{i}$ the solid solubility, and the subscripts o and $s$ indicate oxygen or metal solute atoms. The rate controlling step in internal oxidation is assumed to be the diffusion of oxygen atoms through an alloy, and furthermore the metal oxide that forms is assumed to have a specific stoichiometry. These ideas and assumptions lead to a 'law' for the number of oxygen atoms penetrating unit area of surface $\left(\mathrm{n}_{\mathrm{O}} / \mathrm{S}\right)$ that is parabolic in time $(\mathrm{t})$, as well as Wagner's 'law' for the position of the oxidation front $(\xi)$ in a specimen that is proportional to $t^{1 / 2}[3,5-11]$.

Recently, thermogravimetric measurements of the ratio of oxygen-to-magnesium atoms have been made as a function of time during internal oxidation of a $\mathrm{Ag}-0.4$ at. \% $\mathrm{Mg}$ alloy between $280-550^{\circ} \mathrm{C}[12,13]$. These measurements demonstrate that the oxidation fixation process occurs in three stages at constant temperature -- as a function of internal oxidation time -- and that significant deviations from Wagner's 'law' exist. The atomic mechanisms for the three stages are suggested to be the following: (1) sub- or hypostoichiometric (oxygen poor) metal-oxygen species are initially formed; (2) these elementary species evolve toward irregular clusters that are oxygen rich; and (3) a portion of the excess oxygen is released and the clusters evolve toward a more compact structure [13]. During the second stage the quantity $n_{0} / S$ is proportional to $t^{1 / 2}$; the fixation of oxygen, however, is 
greater than predicted by Wagner's theory [13]. In summary, the thermogravimetric measurements show that the classical picture of internal oxidation is considerably more complicated than had been envisaged, and that the specific atomic mechanisms by which metal oxide precipitates evolve are uncertain.

Also recently internal oxidation has been used as a means to produce metal/metal oxide heterophase interfaces for study via high resolution transmission clectron microscopy [14-20] or atom-probe field-ion microscopy (APFIM) [18-20]. The technique of internal oxidation is a convenient method to control the diameter and number density of metal oxide precipitates, and thereby obtain a reasonable probability of finding these heterophase interfaces -- with a high frequency -- employing high-resolution microscopic studies. Many of the metal oxides produced by intemal oxidation have a simple cube-on-cube orientation relationship with the matrix. For example, $\mathrm{MgO}$ precipitates in a $\mathrm{Cu}$ matrix have an octahedral morphology with the facets of the octahedra being $\{111\}$-type planes [18-20]. Much theoretical $[21,22]$ and experimental effort [14] has focused on the nature of the chemical sequence across metal/metal oxide hetcrophase interfaces. Employing APFIM we have demonstrated that the chemical sequence is CulOIMgl... across the $\{111\}$-type planes that form heterophase interfaces in the $\mathrm{Cu} / \mathrm{MgO}$ system.

During the course of the above investigation -- and research on internal oxidation of $\mathrm{Ni}(\mathrm{Cr})$ to form $\mathrm{Cr}_{2} \mathrm{O}_{3}$ precipitates -- we discovered that it is possible to detect directly nonstoichiometric clusters of metal oxides utilizing APFIM, and thereby study the nucleation and growth of metal oxide precipitates in temary alloys -- two metal species plus oxygen. In this paper we present the first atomic scale evidence -- based on APFIM observations of the Cu-MgO system -- of the nucleation and growth phenomena for metal oxide precipitates in a metal matrix. The results demonstrate that it is possible to follow the complete evolution of metai oxide precipitates starting with the smallest elemental clusters formed from metal solute-atoms and oxygen -- that is, metal solute-atom or metal-oxygen dimers.

\section{Experiments}

The following single phase alloys were fabricated from ASARCO copper (99.998+ at.\% pure) and Johnson Matthey magnesium (99.98 at.\% pure): $\mathrm{Cu}-0.16$ at.\% Mg, Cu-0.7 at.\% $\mathrm{Mg}$ and $\mathrm{Cu}-2.8$ at.\% Mg. The Cu(Mg) alloys were prepared by melting the elements in a graphite crucible sealed under an argon atmosphere in a quartz tube to form cylindrically-shaped ingots. These alloys were homogenized by arc melting them four to five times, followed by an anneal at $1273 \mathrm{~K}$ for three days in an argon atmosphere. Wires of these alloys with a diameter of $250 \mu \mathrm{m}$ were internally oxidized using the so-called Rhines pack method [2]; the temperature employed was $1173 \mathrm{~K}$ and an internal oxidation time of $1800 \mathrm{sec}$ was used. Conventional transmission electron microscopy was used to study the diameters and number densities of metal oxide precipitates, and high resolution microscopy was employed to demonstrate that the precipitates are octahedral shaped with the facets being $\{111\}$-type planes. The atom-probe field-ion microscope (APFIM) experiments were performed, with the specimens maintained at $35 \mathrm{~K}$, using a pulse fraction (f) of 0.1 and a pulse frequency of $15 \mathrm{~Hz}[18-20]$.

\section{Experimental Results}

Figures 1 to 4 exhibit four integral profiles that were obtained by collecting pulsed-desorbed ions -. - and measuring their mass-to-charge state ratios one at a time -- from a 'boring' taken along the [111] direction that is parallel to the central axis of an internally oxidized $\mathrm{Cu}-0.16$ at.\% $\mathrm{Mg}$ wire specimen. An integral profile is obtained by continuously applying a series of high-voltage pulses that results in the atom-by-atom dissection of individual atomic planes of a specimen; an individual plane of atoms is completely dissected and analyzed without interference from the atomic plane below it. This method and its physics are described in detail elsewhere [23-27]. The region along the central axis of a specimen is the last one to be internally oxidized as it is farthest from the surface of a cylindrically-shaped specimen. First, Fig. 1 shows an integral profile of the cumulative number of $\mathrm{Mg}$ or $\mathrm{O}$ events 
versus the cumulative number of $\mathrm{Cu}$ plus $\mathrm{Mg}$ plus $\mathrm{O}$ events collected from a single plane of atoms containing a total of 100 atoms; for clarity the $\mathrm{Cu}$ signal is not exhibited in this integral profile nor in the three others shown. It is clear that no $\mathrm{O}$ atoms are present in this integral profile but there are clusters of $\mathrm{Mg}$ atoms present -- that is, there is clustering of $\mathrm{Mg}$ atoms in a $\mathrm{Cu}$ matrix without the formation of $\mathrm{MgO}$. This is direct proof that the $\mathrm{Mg}$ atoms have sufficient mobility to form small solute-atom clusters. Second, Fig. 2 exhibits another integral profile that demonstrates a completely different type of cluster -- in this case a cluster consisting of five $\mathrm{Mg}$ and six $\mathrm{O}$ atoms is detected; note that this cluster is hyperstoichiometric with the ratio $5 \mathrm{Mg}: 6 \mathrm{O}$. Third, Figure 3 exhibits another integral profile that shows the detection of a hyperstoichiometric magnesium oxide cluster with the ratio $2 \mathrm{Mg}: 50$. And, finally, Fig. 4 exhibits an integral profile that contains a total of 30,000 events. This integral profile shows the presence of three hypostoichiometric magnesium oxide clusters: the three clusters have $\mathrm{Mg}: \mathrm{O}$ ratios of $6.36 \mathrm{Mg}: 1 \mathrm{O}$, $3.91 \mathrm{Mg}: 1 \mathrm{O}$ and $5.63 \mathrm{Mg}: 1 \mathrm{O}$. These four integral profiles directly and clearly demonstrate that the instantaneous formation of stoichiometric $\mathrm{MgO}$ is not the atomic mechanism by which internal oxidation occurs.

\section{Conclusions}

The APFIM results presented herein demonstrate, in a very direct and vivid manner, that the process of internal oxidation does not result directly in the nucleation and growth of metal oxide precipitates that are exactly stoichiometric -- in the case presented $\mathrm{MgO}$-- at the earliest stages of the formation of a metal oxide precipitate. Rather both hypo- and hyperstoichiometric clusters form as well as the clustering of magnesium atoms. The clusters that we observe are clearly precursors to larger precipitates (>1 nm diameter) that are observed via field-ion [18-20] or high resolution electron microscopy [14-20]; For example, Fig. 2 in reference [18] exhibits a field-ion micrograph of a $7.3 \mathrm{~nm}$ diameter $\mathrm{MgO}$ precipitate in a $\mathrm{Cu}$ matrix. Our results also demonstrate that the entire process is considerably more complicated than had been envisaged in the widely used classical model of internal oxidation [3,511]. Furthermore, our results lend credence to the results of the thermogravimetric measurements [12,13], reviewed in the Introduction, where indirect evidence was presented for hypo- and hyperstoichiometric $\mathrm{MgO}$ clusters in an internally oxidized $\mathrm{Ag}-0.4$ at.\% $\mathrm{Mg}$ alloy. In addition, our results demonstrate that the $\mathrm{Mg}$ solute atoms can cluster prior to being internally oxidized, and that both hypo- and hyperstoichiometric clusters of magnesium oxide form as the position of the oxidation front $(\xi)$ moves through a specimen. Thus, we have demonstrated that the atomic mechanisms for internal oxidation of a solute atom, such as $\mathrm{Mg}$, occurs as a result of series of reactions that involve the formation clusters of $\mathrm{Mg}$ atoms that are internally oxidized to produce both hypo- and hyperstoichiometric metal oxide clusters. The latter must evolve in time towards dense precipitates with a specific mean stoichiometry or perhaps a range of stoichiometries. Any deviation from exact stoichiometry can, of course, be accomodated by the formation of Schottky-type point defects [28-30]. Our experiments also demonstrate that it is now possible to follow, on an atomic scale, the process of internal oxidation from its very earliest stages to the point where metal oxide precipitates are visible by different high resolution microscopies.

\section{Acknowledqments}

This research is supported by the U. S. Department of Energy Office of Basic Energy Science grant No. DEFG02-89ER45403 (Dr. M. Kassner and Dr. J. B. Darby Jr., grant officers). It also utilized central facilities of the National Science Foundation funded Materials Research Center at Northwestern University. Dr. K. L. Merkle is supported by the U. S. Department of Energy, BES-Materials Science under contract \#W-31-109-ENG-38 at Argonne National Laboratory. 


\section{References}

1. C. S. Smith, Min. and Met. 11, 213 (1930); Min. and Met. 13, 481 (1932); J. Inst. Metals 46, 49 (1931).

2. F. N. Rhines, Trans. AIME 137, 246 (1940); F. N. Rhines, W. A. Johnson and W. A. Anderson, Trans. AIME 147, 205 (1942).

3. J. L. Meijering and M. J. Druyvesteyn, Philips Res. Rep. 2, 81 (1947).

4. H. C. Furtado and V. L. A. da Silveira, IEEE Trans. Comp., Hybrids, Manuf. \& Manuf. Technol. 11, 68 (1988).

5. C. Wagner, Z. Elektrochemie 63,772 (1959).

6. L. S. Darken, Trans. Am. Soc. Metals, 54, 600 (1961).

7. G. Böhm and M. Kahlweit, Acta Metall. 12,641 (1964).

8. M. Kahlweit, Prog. Chem. Solid State 2, 134 (1965).

9. R. A. Rapp, Corrosion-Nat. Assoc. Corr. Eng. 21, 382 (1965).

10. J. L. Meijering, Advan. Mater. Res. 5, 1 (1971).

11. H. Schmalzried, Ber. Bunsenges. Phys. Chem. 87, 551 (1983).

12. L. Charrin, A. Combe, and J. Cabané, Oxid. Metals 17, 65 (1992).

13. B. M. Semega, L. Charrin, A. Combe and J. Aride, Philos. Mag. A, 1139 (1992).

14. G. Necker and W. Mader, Phil. Mag. Letts. 58, 205 (1988); W. Mader, Z. Metallkde 80, 139 (1989); W. Mader and B. Maier, Colloq. Phys. (Paris) 51, Colloq. C1, 867 (1990); W. Mader, Mater. Res. Soc. Symp. Proc. 238, 763 (1992).

15. T. Muschik and M. Ruhle, Phil. Mag. A 65, 363 (1992).

16. K. L. Merkle, M. I. Buckett and Y. Gao, Acta Metall. Mater. 46, S249 (1992); Y. Gao and K. L. Merkle, Mater. Res. Soc. Symp. Proc. 238, 775 (1992).

17. P. Lu and F. Cosandey, Acta Metall. Mater. 40, S259 (1992); P. Lu, I.-C. Tung and F. Cosandey, Mater. Res. Soc. Symp. Proc. 238, 781 (1992).

18. H. Jang, D. N. Seidman and K. L. Merkle, Scripta Metall. Mater. 26, 1493 (1992).

19. H. Jang, D. N. Seidman and K. L. Merkle, accepted for publication in Mater. Sci. Forum (1992).

20. H. Jang, D. N. Seidman and K. L. Merkle, accepted for publication in Interface Sci. (1992).

21. A. J. Freeman and Chun Li, in Metal-Ceramic Interfaces: Proceedings of an International Workshop, edited by M. Rühle, A. G. Evans, M. F. Ashby and J. P. Hirth (Pergamon, Oxford, 1990), pp. 2-8; Chun Li and A. J. Freeman, Phys. Rev. B 43, 780 (1991).

22. P. Blöchl, G. P. Das, H. F. Fischmeister and U. Schönberger, in Metal-Ceramic Interfaces: Proceedings of an International Workshop, edited by M. Ruhle, A. G. Evans, M. F. Ashby and J. P. Hirth (Pergamon, Oxford, 1990), pp. 9-14.

23. D. N. Seidman, J. Phys. F: Metal Phys. 3, 393 (1973); D. N. Seidman, in Encyclopedia of Materials Science and Engineering, edited by M. B. Bever (Pergamon, Oxford, 1986), pp. 1741-1744; D. N. Seidman, in Materials Interfaces, edited by D. Wolf and S. Yip (Chapman \& Hall, London, 1992), Chapt. 2, pp. 5884; S. M. Foiles and D. N. Seidman, in Materials Interfaces, edited by D. Wolf and S. Yip (Chapman \& Hall, London, 1992), Chapt. 19, pp. 497-515.

24. R. Wagner, Field-Ion Microscopy (Springer-Verlag, Berlin, 1982), Chapt. 2, pp. 12-19, 25-33.

25. T. Sakurai, A. Sakai and H. W. Pickering, Atom-Probe Field-Ion Microscopy and its Applications (Academic, Boston, 1989), Chapt. 2, pp. 18-41.

26. M. K. Miller and G. D. W. Smith, Atom Probe Microanalysis (Materials Research Society, Pittsburgh, PA, 1989), Chapt. 1, pp. 1424.

27. T. T. Tsong, Atom-Probe Field-Ion Microscopy (Cambridge Univ., Cambridge, 1990), Chapt. 2, pp. 31-71.

28. P. Kofstad, Nonstoichiometry, Diffusion, and Electrical Conductivity in Binary Metal Oxides (R. E. Krieger, Malabar, FL, 1983), Chapt. 7, pp. 121-127.

29. C. P. Flynn, Point Defects and Diffusion (Clarendon, Oxford, 1972), Chapt. 5, pp. 207-216.

30. W. D. Kingery, H. K. Bowen and D. R. Uhlmann, Introduction to Ceramics (John Wiley, New York, 1976), 2nd ed., Chapt. 4, pp. 157-164. 


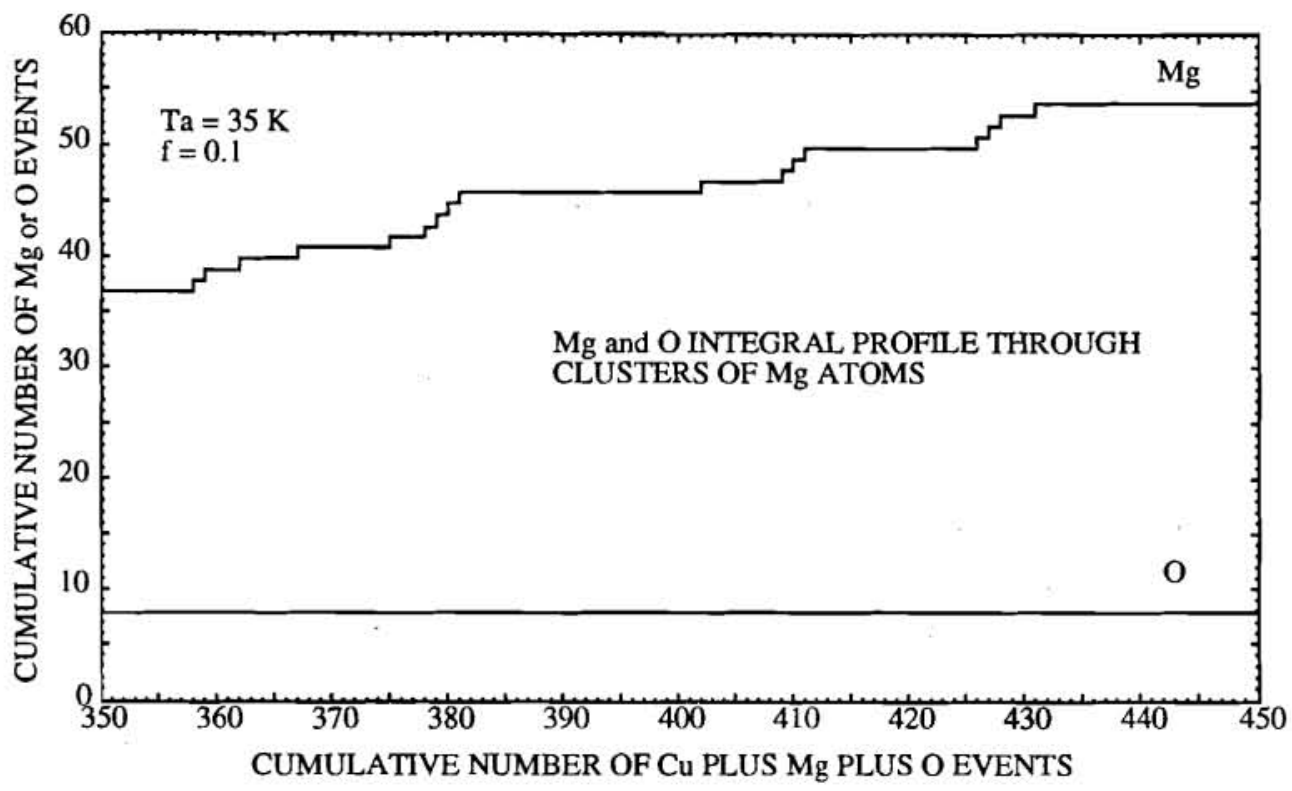

FIG. 1. An integral profile through clusters of $\mathrm{Mg}$ atoms; for clarity the $\mathrm{Cu}$ signal is not exhibited; this profile was recorded at a specimen temperature of $35 \mathrm{~K}$, and a pulse fraction $(\mathrm{f})$ of 0.1 and a pulse frequency of $15 \mathrm{~Hz}$ were employed. This data demonstrates that no oxygen atoms are present in this profile but there are clusters of $\mathrm{Mg}$ atoms -- that is, there is clustering of $\mathrm{Mg}$ atoms in a $\mathrm{Cu}$ matrix without the formation of magnesium oxide.

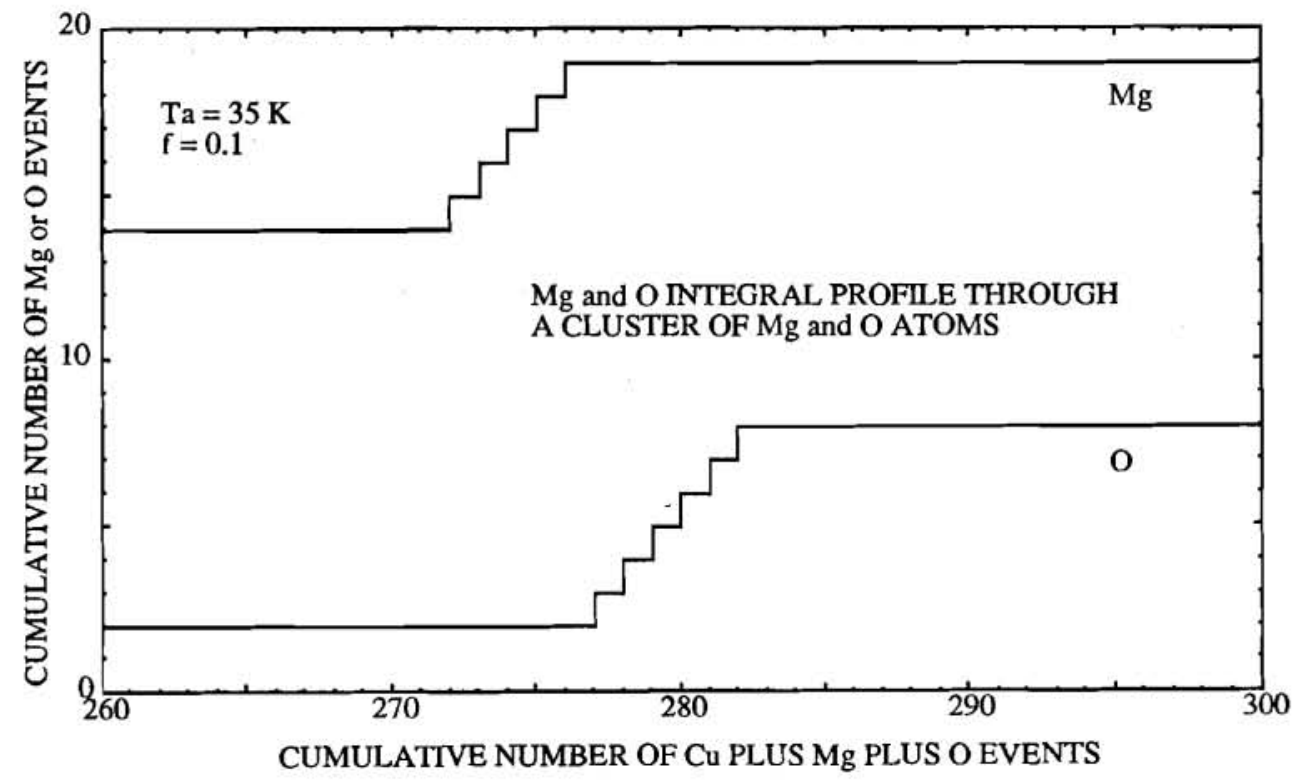

FIG. 2. An integral profile through a cluster of $\mathrm{Mg}$ and $\mathrm{O}$ atoms; for clarity the $\mathrm{Cu}$ signal is not exhibited; this profile was recorded at specimen temperature of $35 \mathrm{~K}$, and a pulse fraction ( $\mathrm{f}$ ) of 0.1 and a pulse frequency of $15 \mathrm{~Hz}$ were employed. This data demonstrates the existence of a hyperstoichiometric cluster of magnesium oxide with the ratio 5 $\mathrm{Mg}: 60$. 


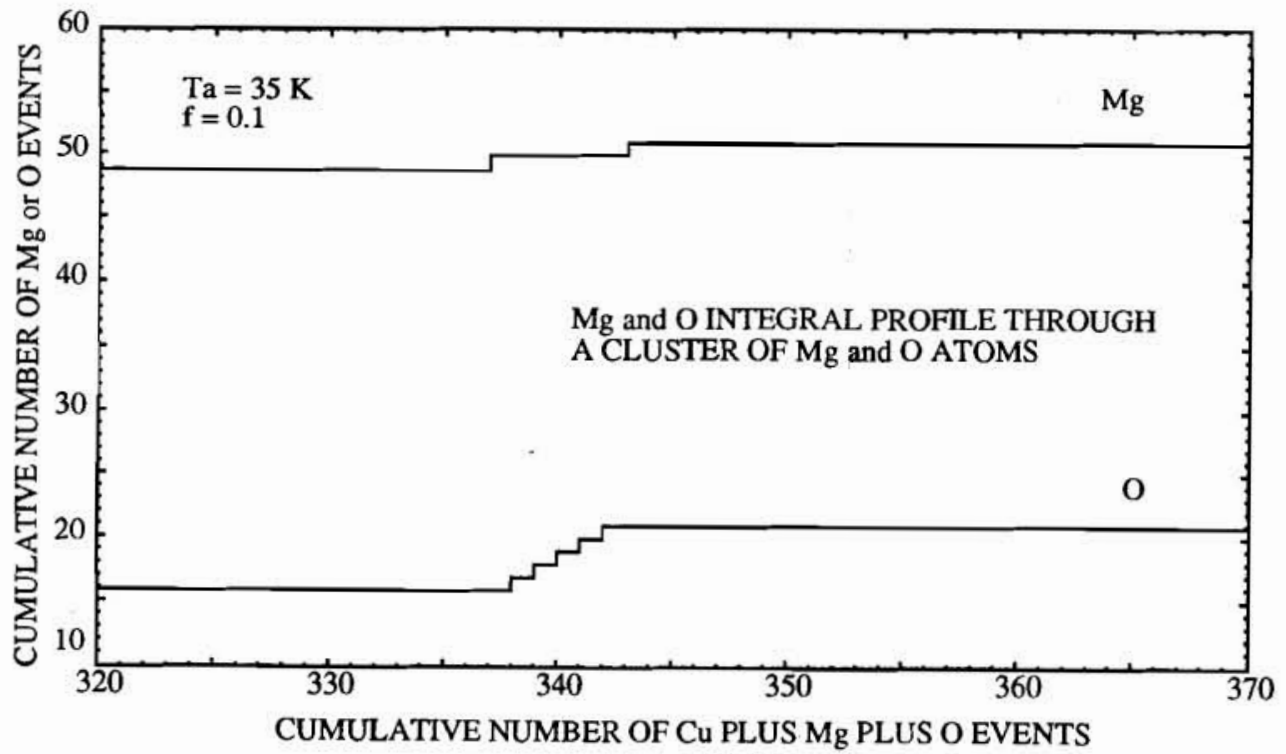

FIG. 3. An integral profile through a cluster consisting of $\mathrm{Mg}$ and $\mathrm{O}$ atoms; for clarity the $\mathrm{Cu}$ signal is not exhibited; this profile was recorded at a specimen temperature of $35 \mathrm{~K}$, and a pulse fraction ( $\mathrm{f}$ ) of 0.1 and a pulse frequency of $15 \mathrm{~Hz}$ were employed. This data exhibits a hyperstoichiometric cluster of magnesium oxide with the ratio $2 \mathrm{Mg}: 5 \mathrm{O}$.

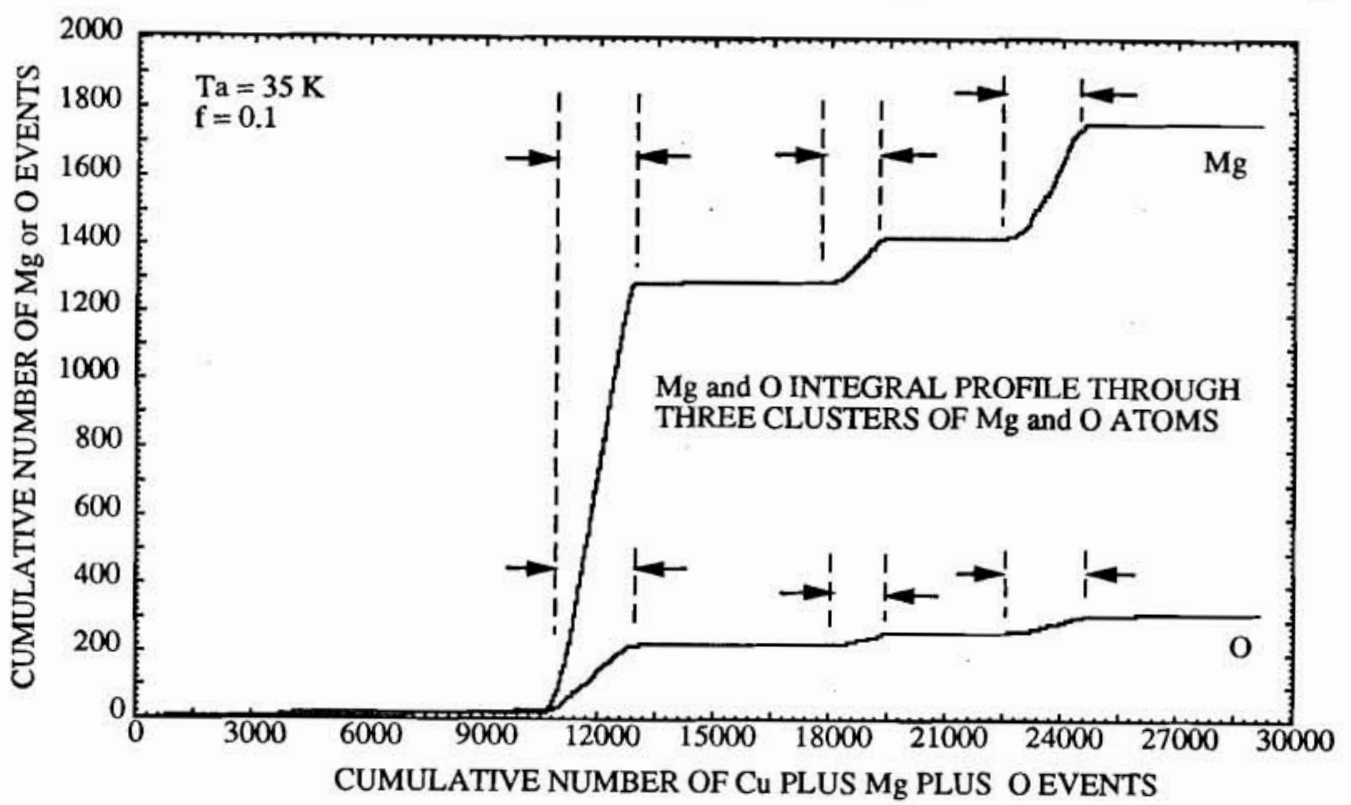

FIG. 4. An integral profile through three clusters of magnesium oxide; for clarity the $\mathrm{Cu}$ signal is not exhibited; this profile was recorded at a specimen temperature of $35 \mathrm{~K}$, and a pulse fraction (f) of 0.1 and a pulse frequency of $15 \mathrm{~Hz}$ were employed. This profile contains a total of 30,000 events and clearly shows the existence of three hypostoichiometric clusters of magnesium; they are indicated by arrows. The three clusters have the following $\mathrm{Mg}$ to O ratios: $6.36 \mathrm{Mg}: 1 \mathrm{O}, 3.91 \mathrm{Mg}: 1 \mathrm{O}$, and $5.63 \mathrm{Mg}: 1 \mathrm{O}$. 